\title{
Experimental investigation on effect of combustion chamber geometry and port fuel injection system for CNG engine
}

\author{
Tanaji Balawant Shinde \\ (Dept-Mechanical engineering, Specialization-Automobile Engineering, NIT Warangal, India)
}

\begin{abstract}
Compressed natural gas $(C N G)$ is the most favorite for fossil fuel substitution because of low pollutant and Carbon dioxide emission. Recently rising fuel cost, energy security and environmental pollution issues are becoming important concerns world over, so amongst the various alternatives CNG is the most practical solution.

There are four methods to inject the CNG into the engine cylinder, such as gas mixer/carburetor injection, manifold injection, port injection and direct injection. In port injection CNG engines, gaseous fuel is injected by fuel injector through intake port into combustion chamber.

This project work presents improvement for air-fuel mixing in the combustion chamber by the use of pressurized flow of $C N G$ inside the cylinder with the help of CNG injector through intake port. The modification is focused on the intake fuelling system. For fuelling system the port injection of CNG gas must be used because of major limitation for other types of fuelling system from availability, installation and emission point of view.

Experimentation work carried out on a Greaves made engine having cubic capacity of 600cc dedicated $C N G$ engine and the effects of $C N G$ injection through modification of combustion chamber geometry on the engine performance in terms of parameters like Brake torque, Brake power, BMEP, BSFC, and Exhaust gas temperature of the engine was examined.
\end{abstract}

Keywords: - Dedicated CNG engine, venturi mixer, Port injection, combustion chamber, performance

\section{Introduction}

Diesel engines are invariably used in transportation and agricultural applications. It is a versatile prime mover due to its high fuel efficiency, low fuel cost, lower maintenance and high reliability. But due to large scale use of diesel fuel, the smoke in the diesel exhaust and gaseous emissions are subjected to stringent legislation. To overcome the difficulty, research has led to development of various alternative fuels. Among the alternative fuels, gaseous fuels are preferred as they do not pose the problem of atomization. Recently, interest has grown in the natural gas and thus, compressed natural gas (CNG) has become important viable alternative fuel. First generation gaseous fuelling system utilizes the mixer system as it requires the least modification to the engine. However, a mixer system resulted in a lower engine volumetric efficiency \& poor engine performance. To increase the performance of the CNG engine, alternative fuelling methods such as port injection \& direct injection are being considered as an option to make $\mathrm{CNG}$ a more favorable vehicle fuel.

Fuel injection systems have been developed \& widely used in modern CNG vehicles because of their potential for emission reductions as well as other performance benefits. By employing an equivalent injection system on alternative fuel vehicles, performance can be optimized.CNG direct injection injector is not commercially available because of some limitation like, it has to withstand high combustion environment (unlike normal gaseous injectors), leakage problems \& durability due to insufficient lubrication effect. In order to overcome this problem, suitability of port fuel injection comes in existence.

It was observed that intake system plays an important role for homogenous mixing thereby lambda becomes unity i.e.1.By maintaining $\mathrm{CNG}$ gas pressure through pressure regulator \& injector at about 5 to 7 bar \& proper design of intake port to avoid swirling action it is possible to obtain stochiometry in the air-fuel mixing. Most of the diesel engine after conversion to $\mathrm{CNG}$ engines having high swirl leads to less fuel economy \& loss in volumetric efficiency. These issues were examined in details \& experimentation was carried out to assess the effect of low swirl \& pressurized fuel flow with the help of injection leading to increase in volumetric efficiency \& engine performance. [1]

The experimentation performed on engine in this project is a Greaves made engine. The engine was basically direct injection diesel engine having $611 \mathrm{cc}$ capacity with compression ratio of $18: 1$.This engine was used for conversion from diesel engine mode to $\mathrm{CNG}$ engine mode. For conversion following changes was made.

1. Replacement of diesel injector by spark plug in the cylinder head

2. Removal of existing diesel fuel injection pump and governor

3. Use of high tension coil \& high tension cable as ignition system

4. Use of venturi which acts as $\mathrm{CNG}$ and air mixer 
5. Change of compression ratio from 18:1 to $12: 1$ by changing combustion chamber geometry.

Baseline engine was already a conversion of diesel engine into CNG engine. The amount of swirl present in converted engine due to intake port geometry is not suitable for CNG operation as engine performance point of view. For better volumetric efficiency the fuel flow of the CNG must be pressurized which is obtained by CNG injector which is situated close to intake port. For improvement of engine performance and keeping emission norms in mind the testing and experimentation was carried out by making following major changes on a given engine.

1. Use of CNG injector close to intake port for pressurizing fuel flow with the help of pressure regulator

2. Selection of suitable combustion chamber geometry keeping same compression ratio

\section{Properties of CNG as compared to Diesel}

\begin{tabular}{|c|c|c|}
\hline Properties & Diesel & CNG \\
\hline Chemical Formula(-) & $\mathrm{C}_{15} \mathrm{H}_{28}$ & $\mathrm{CH}_{4}$ \\
\hline Molecular weight(-) & 208 & 16 \\
\hline Carbon Content(\%m) & 86.1 & 75 \\
\hline Hydrogen Content (\%m) & 13.9 & 25 \\
\hline Oxygen Content $(\% \mathrm{~m})$ & 0 & 0 \\
\hline Density liquid at $20^{0}(\mathrm{Kg} / \mathrm{l})$ & 0.840 & - \\
\hline Lower Heating Value $(\mathrm{MJ} / \mathrm{Kg})$ & 42.7 & 47.7 \\
\hline Heat of Evaporation $(\mathrm{KJ} / \mathrm{MJ})$ & $\approx 6.0$ & - \\
\hline Cetane Number $(-)$ & $45-55$ & - \\
\hline Octane Number $(-)$ & - & $\approx 130$ \\
\hline $\mathrm{Co}_{2}$ Emission $(\mathrm{g} / \mathrm{MJ})$ & 74.2 & 57.7 \\
\hline
\end{tabular}

High octane number and low $\mathrm{Co}_{2}$ emission of $\mathrm{CNG}$ leads to use engine at high compression ratio because it provides better knock resistant for increasing compression ratio.

\section{Baseline engine Specification}

\begin{tabular}{|c|c|c|}
\hline Sr. No. & Parameters & Value or type \\
\hline 1. & Bore $(\mathrm{mm}) \times$ Stroke $(\mathrm{mm})$ & $92 \times 92$ \\
\hline 2. & No. of cylinder & Single $(1)$ \\
\hline 3. & Displacement(cc) & 611 \\
\hline 4. & Aspiration & Natural \\
\hline 5. & Rated speed(r/min) & 3000 \\
\hline 6. & Cooling type & Water cooled \\
\hline 7. & Compression ratio & $12: 1$ \\
\hline 8. & Max power & $11 \mathrm{hp} @ 2800 \mathrm{rpm}$ \\
\hline 9. & Max torque & $37 \mathrm{Nm} @ 1400$ \\
\hline 10 & Air -Fuel mixing & venturi \\
\hline
\end{tabular}

\section{CNG Engine design requirements}

CNG Engine design requirements for better performance \& emission:-

- Combustion chamber \& piston with high squish area

- Port designs for optimum tumble or swirl

- Valve timing

- Improved material for valve \& valve seat

- Location of injectors close to intake

On the basis of above requirements for better engine operation, performance \& emission point of view the inlet fuelling systems and combustion chamber geometry of engine must be considered. For fuelling system port 
injection of CNG must be used. Another way on improving the burning rate of CNG is to generate charge motion inside the combustion chamber by squishing. High levels of turbulence is generated from the squish which have an effect on increasing burning rates, which result in the improvement of thermal efficiency.[2]

\section{Selection \& suitability of Port fuel(CNG) injection system}

- Startability

- Better engine output

- Deceleration cutoff possible

- High potential for meeting emission norms

- Air-fuel ratio control

- Narrow production tolerance [3]

\section{Modifications}

\subsection{Compression ratio and Piston combustion chamber geometry}

The compression ratio of existing diesel engine is 18:1.when converting the diesel engine to CNG mode the compression ratio is reduced to $12: 1$ by changing piston crown geometry. Combustion chamber geometry of diesel engine is not suitable for CNG engine because of diesel engine forms heterogeneous mixture with air \& this process takes place with respect to swirl \& turbulence. But for CNG engine swirl must be removed for obtaining homogenous mixture. For this reason suitable combustion geometry of bowl shape must be selected. Bowl shape piston geometry helps in increase of squish area and proper mixing of CNG with air.

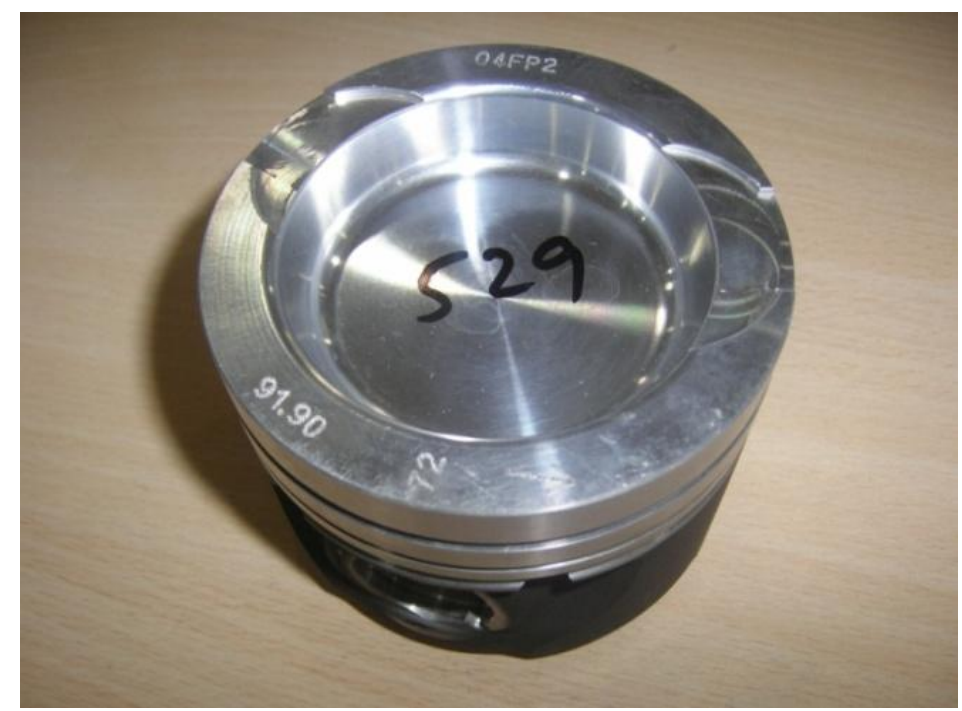

6.2.Fuel injection by injector

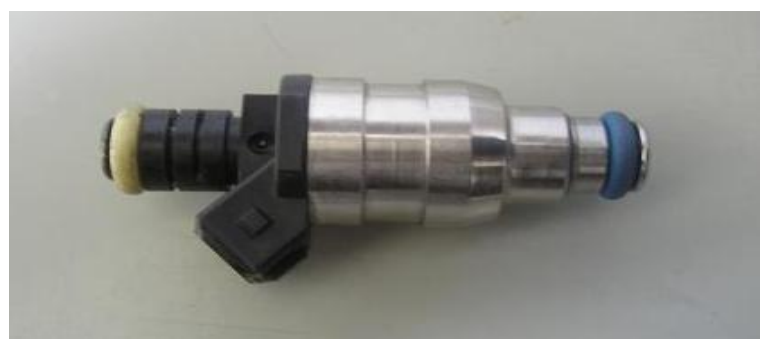

The fuel injector sprays the fuel into intake port at system pressure. They inject the precise metering of the quantity of fuel required by engine. The high pressure natural gas from the gas cylinder is first pass through the gas pressure regulator to reduce the pressure in the range of 5 to 6 bar. Then gas is supplied into engine via CNG injector.

\section{Experimentation}

For testing and experimentation engine can be mounted on engine test bed with eddy current dynamometer for measurement of performance parameters at full throttle. Engine arrangement is based on Venturi based and port injection system which is shown below. 

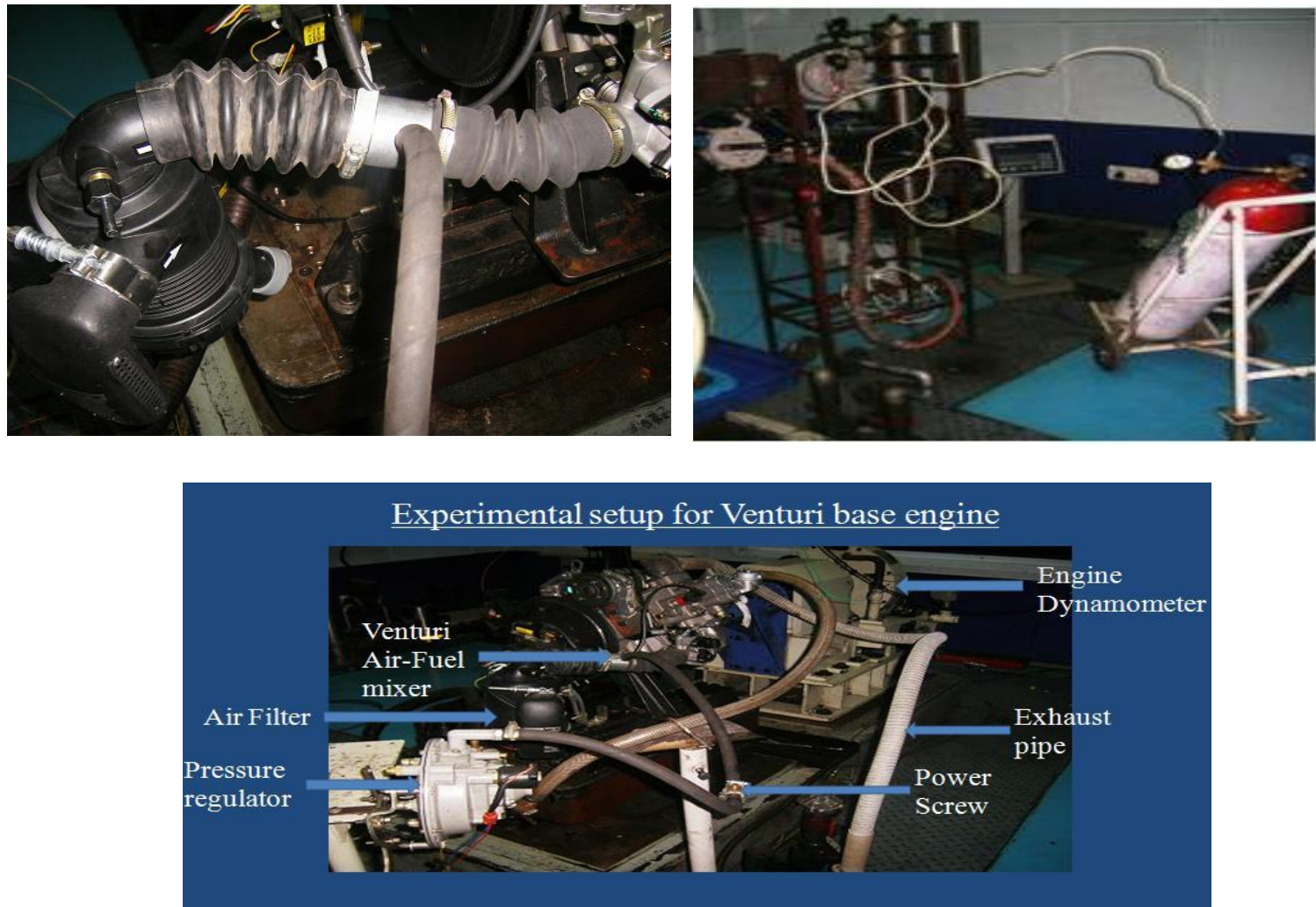

\section{Results and discussion}

\subsection{Torque Vs Speed}

Baseline engine-venturi base

Modified engine- port injection with bowl type combustion chamber

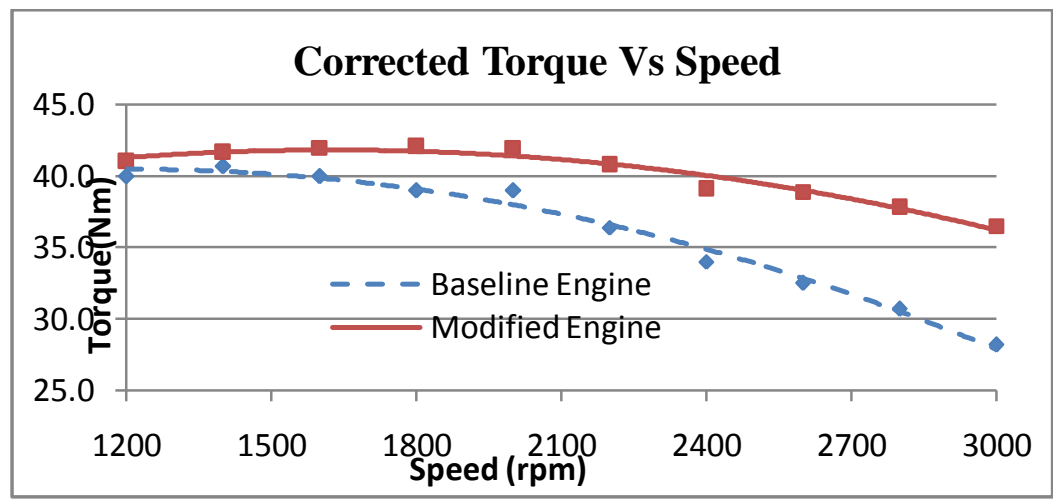

Fig.1.Effect of bowl type piston and port injection on Torque

Pressurized flow of $\mathrm{CNG}$ by injector close to intake leads to better mixing and have better possibility to achieve stochiometry. Combustion chambers for CNG are designed based on parameters like turbulence, swirl and squish. CNG having low laminar flame speed leads to less force development on the piston during expansion. This problem can be solved by developing combustion chamber specifically for natural gas. Reducing turbulence in the combustion chamber leads to lower resistance to flow thereby improving the breathing capacity of the engine resulting in an increased flame speed. After experimentation it was found that maximum increment of torque. 


\subsection{Power Vs speed}

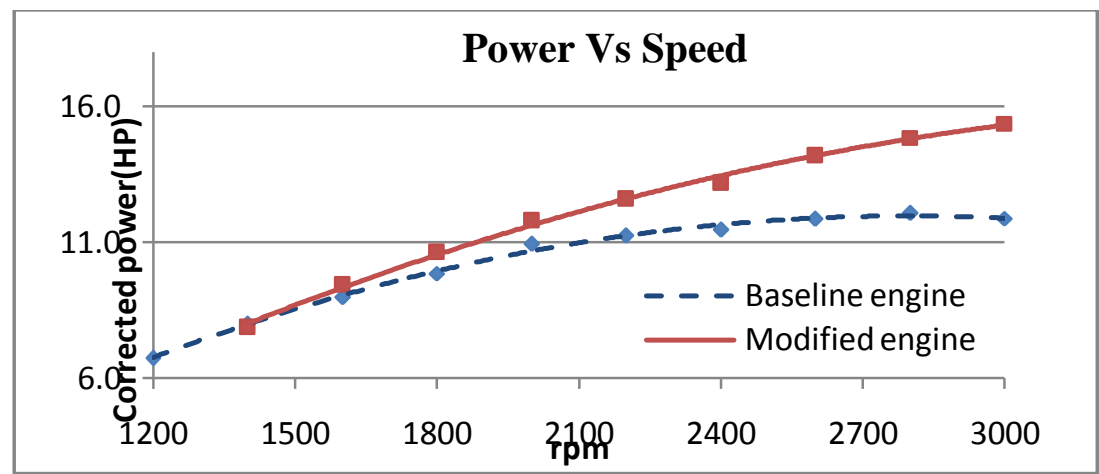

Fig.2.Effect of bowl type piston and port injection on power

The main purpose of running an engine is mechanical power. Measurement of power involves measurement of torque. As torque increases power increases .Improvement in the rated power was observed. Fuel conversion efficiency is also one of the major considerations for increase of power. Fuel conversion efficiency is mainly depends on combustion chamber geometry. Based on CNG as an engine fuel and its properties the combustion chamber must be modified with bowl in type piston.

\subsection{Exhaust temperature Vs Speed}

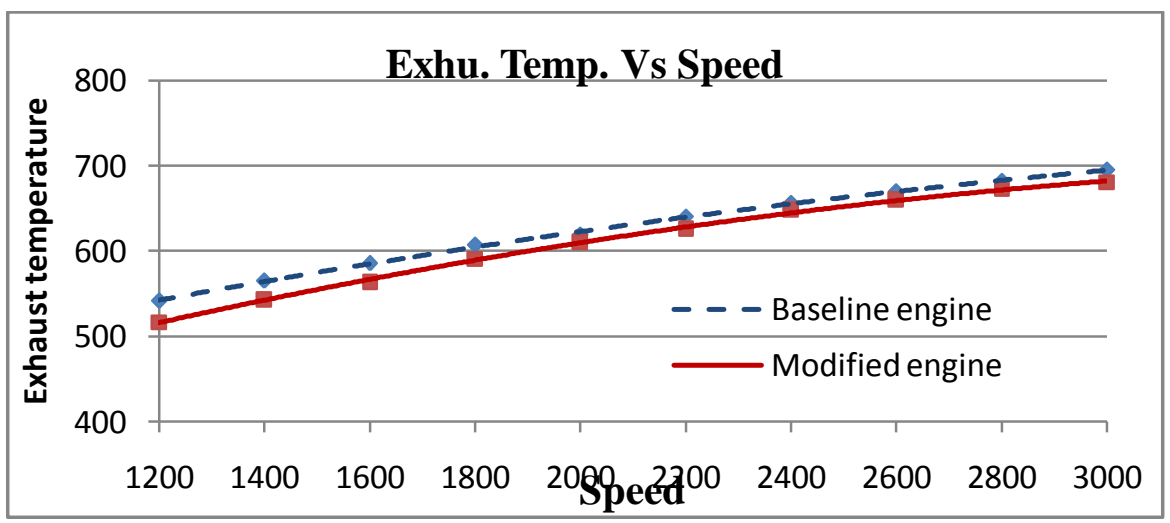

Fig.3.Effect of bowl type piston and port injection on exhaust temperature

Graph and experimental values shows Combustion is very good in modified engine. Better Combustion gives less Exhaust gas Temperature because of proper burning of fuel before opening Exhaust valve. Experimental values shows the maximum reduction can be observed @ 1200RPM with 4.6\%.

\subsection{BMEP Vs Speed}

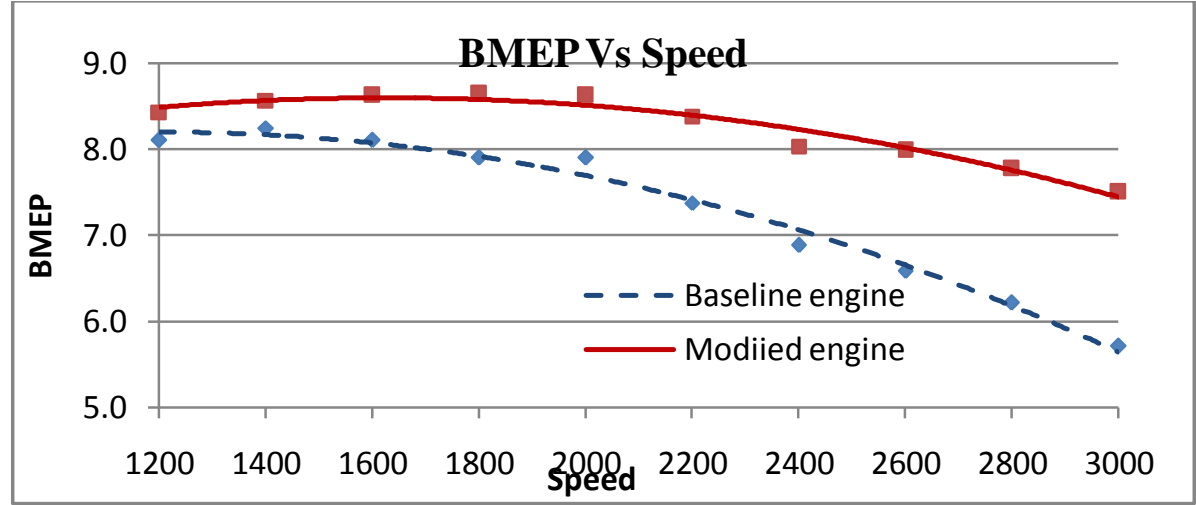

Fig.4.Effect of bowl type piston and port injection on BMEP 
Improvement in power and torque leads to improvement in BMEP.

\subsection{BSFC Vs Speed}

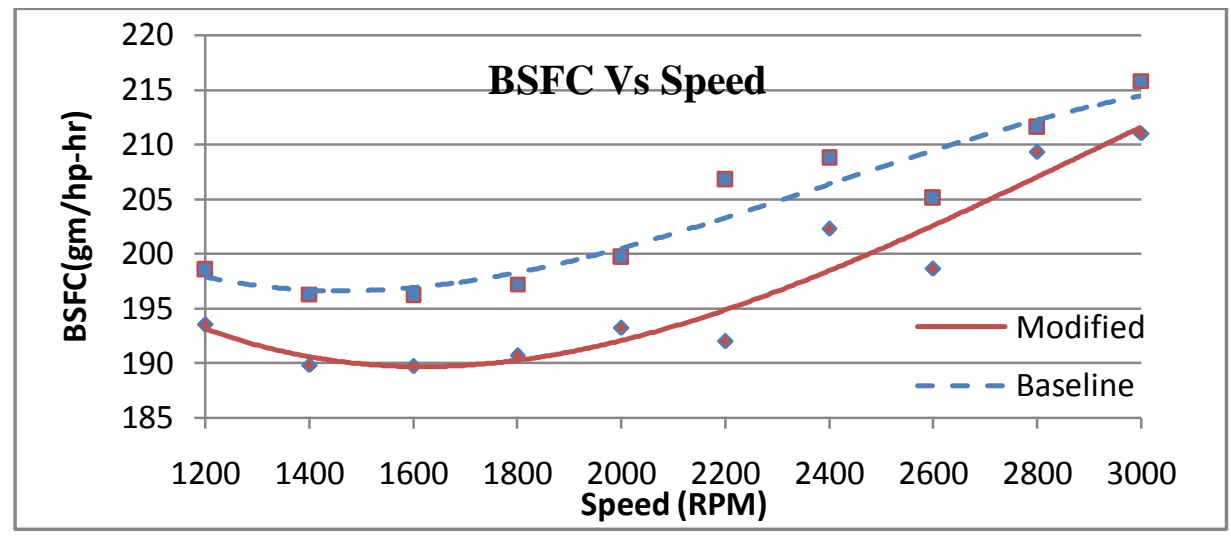

Fig.5.Effect of bowl type piston and port injection on BSFC

Graph shows clearly BSFC in modified engine is less compare with baseline engine. This shows combustion is very good in modified engine. Better combustion gives less BSFC because of proper combustion of fuel inside the cylinder

\section{Conclusions}

9.1.The experimental investigation was carried out for the performance of G600WG (water cooled gasoline) engine with major modifications in combustion chamber geometry for maintaining suitable compression ratio and CNG port injection by injector through intake port

9.2. It was found that due to above mentioned modifications; the performance of the engine was influenced to an optimum level. Optimum improvement of engine performance can be observed in brake power, brake torque and BMEP performance parameters.

9.3. Reduction in exhaust temperature also observed because of proper combustion of fuel inside the cylinder before opening of exhaust valve.

9.4. The experimental results of both baseline and modified engine were validated with permissible variation of $10 \%$ in almost all cases of engine performance parameter.

\section{Acknowledgements}

I am grateful to Dr. G Amba Prasad Rao, Associate Professor, NIT Warangal for his steady help, valuable suggestions and co-operation.

I am grateful to Mr. V Suresh Babu, Assistant Professor, NIT Warangal for his guidance, support, cooperation and encouragement needed to fulfill the project work

I consider myself to be fortunate to get this opportunity to explore this field of IC Engines under the guidance of Mr. Girish S. Khairnar, Associate General Manager (R\&D), Greaves Cotton Ltd., Aurangabad. I am sincerely grateful to him for his valuable guidance, motivation, and support at all stages of the project work, right from conception of idea to the realization of project.

\section{Journal Papers:}

\section{References}

[1] J.P.Mohite and S.D. Rairikar "Development of BS-III CNG Engine for Heavy Commercial Vehicle" (2009-26-038)

[2] MARDANI "Development of Intake System for Improvement of Performance of Compressed Natural Gas Spark Ignition Engine" octo2004.

[3] P.K. Sharma, "Gaseous fuelled vehicle Technology" AVL Technical Seminar April24, 2007.

\section{Books:}

1. J.B Heywood, Internal Combustion Engine Fundamentals .Mc Graw Hill Publication, 1988. 